\title{
How Can We Study Cultural Aspects of Human Development?
}

\author{
Editor's I ntroduction
}

Barbara Rogoff, Editor-in-Chief

For this special edition of Human Development, I invited a distinguished panel of scholars to each write a brief position paper on the topic of using the concept of culture in research on human development. Their charge was not to provide more definitions of culture, but rather to contribute to an interdisciplinary discussion of how we can investigate cultural aspects of human development.

Questions of how to examine cultural processes in the lives of children and families are increasingly pressing, as researchers are called on to include a broader representation of ethnic groups in their studies. Although disciplinary boundaries sometimes pit one approach to the study of cultural processes against another, with research traditions prioritizing their own assumption systems, I believe that it is essential for our fields to use a range of approaches. Diversity of approaches is a resource for progress in the intellectual challenges we face in understanding cultural processes in human development.

Therefore, the participants in this discussion represent a variety of disciplinary and interdisciplinary backgrounds that address cultural aspects of human development - especially developmental psychology, anthropology, and education. It is noteworthy that many individuals (those represented in this special issue as well as others) have fruitfully bridged the perspectives of several disciplines or have participated in interdisciplinary programs that bridge between traditions.

To initiate the discussion, I sent the contributors a draft of a paper addressing the need for our fields to include integrated, dynamic approaches in researching cultural aspects of development. (A revised version of this paper serves as the starting contribution to this special issue.) I asked the contributors to use this paper as a springboard for bringing to the discussion their own ideas about how research on cultural aspects of human development should proceed.

I am grateful to the contributors for their forthrightness and wisdom. They do not all agree with each other - and this is what I hoped in inviting them. Their stances reveal how central questions as well as relevant methods vary with the in-

\section{KARGER}

Fax +41613061234

E-Mail karger@karger.ch

www.karger.com

(ㄱ)2002 S. Karger AG, Basel

0018-716X/02/0454-0209\$18.50/0

Accessible online at:

www.karger.com/journals/hde
} 
tellectual traditions of the different fields. In addition, several central terms (such as culture, ethnicity, holism, membership, variables, factors, qualitative, and quantitative) seem to be used differently according to the different traditions - requiring scholars to consider the basis for assumptions underlying the concepts. Readers may also detect important differences across the papers in the key questions and in systems of assumptions for addressing them.

I am confident that attempts to understand and bridge these differences can help prepare us for the next decades of research examining how humans develop as participants in their cultural communities. This topic is of utmost importance for research on human development as well as for contributing to the lives of children and communities. 